\title{
Seminars in Thrombosis and Hemostasis, Volume 32, Supplement 2, 2006: Current and Future Hemophilia Treatment Options Based on the 15th Annual Hemophilia Research Study Update
}

\author{
Guest Editor, Leonard A. Valentino, M.D.
}

In the above-mentioned supplement, two of the following Guest Editors were not acknowledged: Edward Gomperts, M.B.B.Ch., M.D., and Bruce Ewenstein, M.D., Ph.D.

Their affiliation information is as follows: Edward Gomperts M.B.B.Ch., M.D., Director of Clinical Research, Childrens Hospital of Los Angeles and Clinical Professor in Pediatrics and Pathology, University of Southern California Keck School of Medicine, Los Angeles, California.

Bruce Ewenstein, M.D., Ph.D., Global Medical Director, Baxter Healthcare Corporation, Westlake Village, California.

Deep Vein Thrombosis and Pulmonary Embolism, Part 1; Guest Editor, Paolo Prandoni, M.D., Ph.D.

Semin Thromb Hemost 2006;32:752. Copyright (C) 2006 by
Thieme Medical Publishers, Inc., 333 Seventh Avenue, New York, NY 10001, USA. Tel: +1(212) 584-4662.

DOI 10.1055/s-2006-951461. ISSN 0094-6176. 